\begin{tabular}{|l|c|c|l|l|l|}
\hline \multirow{2}{*}{$\mathcal{L}$} & T O P S & $\mathbf{1 2 1 7 8}$ & \multirow{2}{*}{ WILEY } & Dispatch: 19.11.15 & CE: Ashokkumar \\
\cline { 2 - 3 } \cline { 5 - 6 } & Journal Code & Manuscript No. & & No. of pages: 26 & PE: Suganya Raju \\
\hline
\end{tabular}

\title{
Climate Justice: High Status Ingroup Social Models Increase Pro-environmental Action Through Making Actions Seem More Moral
}

\author{
Joseph Sweetman, ${ }^{\mathrm{a}}$ Lorraine E. Whitmarsh ${ }^{\mathrm{b}}$ \\ ${ }^{a}$ University of Exeter \\ ${ }^{\mathrm{b}}$ Cardiff University
}

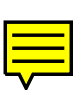

Received 30 June 2014; received in revised form 13 October 2015; accepted 31 October 201.

\begin{abstract}
Recent work has suggested that our cognitive biases and moral psychology may pose significant barriers to tackling climate change. Here, we report evidence that through status and groupbased social influence processes, and our moral sense of justice, it may be possible to employ such characteristics of the human mind in efforts to engender pro-environmental action. We draw on applied work demonstrating the efficacy of social modeling techniques in order to examine the indirect effects of social model status and group membership (through perceptions of efficacy, pro-environmental identity and moral judgments of how fair it is for individuals to perform particular pro-environmental actions) on pro-environmental action tendencies. We find evidence that high (vs. low) status models increase pro-environmental action, in part, through making such actions seem morally fairer to undertake. This effect of high status models only occurs when they share a meaningful ingroup membership with the target of influence. Further, we find evidence that this conditional effect of high status models may also have a direct impact on action tendencies. While the exact behaviors that are influenced may vary across student and non-student samples, we argue that a focus on the "justice pathway" to action and the socialcognitive features of models may offer a good opportunity for cognitive and behavioral scientists to integrate insights from basic research with those stemming from more applied research efforts.
\end{abstract}

Keywords: Social model; Status; Pro-environmental action; Fairness; Morality; Efficacy; Social identity

Correspondence should be sent to Dr. Joseph Sweetman, Psychology, College of Life and Environmental Sciences, University of Exeter, Exeter EX4 4QG, UK, E-mail: j.p.sweetman@exeter.ac.uk 


\section{Introduction}

The science is clear; climate change requires individual, political, and institutional action to address it (IPCC, 2014). Applied cognitive and behavioral scientists have focused their efforts on establishing evidence-based behavioral interventions, often combining multiple interventions from different theoretical perspectives (see Osbaldiston \& Schott, 2012). Basic research has focused on identifying the perceptions, attitudes, and judgments that predict pro-environmental motivation and action (see Bamberg \& Möser, 2007; Hines, Hungerford, \& Tomera, 1987). Recently efforts have been made to examine how cognitive biases and the general structure of the human mind may act as barriers to pro-environmental cognition and action (Gifford, 2011; e.g.,.Markowitz \& Shariff, 2012). The research attempts to build upon all of this earlier work by examining how evidence-based behavioral interventions can benefit from what we know about such cognitive biases and barriers. More specifically, we employ psychological models of collective action (Van Zomeren, Postmes, \& Spears, 2008) to examine whether the social status and group membership (Fiske, Cuddy, \& Glick, 2007; Henrich \& Gil-White, 2001; see Tajfel \& Turner, 1979) of social models (see Bandura, 1977) influences personal and political pro-environmental action. This approach is of key importance as it both provides a better understanding of the psychological processes through which our best-evidenced interventions operate and offers the potential to turn biases and barriers into constructive aspects of pro-environmental interventions.

\section{Explaining social model effects through collective action constructs}

Our cognitions, motivations, and actions regarding climate change do not take place in a social vacuum. Rather, it has long been recognized that social influence acts as a pervasive aspect of human affairs (see Aristotle, 2005). Indeed, social-psychological theories take such influence to be a fundamental principle guiding the scientific understanding of human behavior (Aronson, 2007; for example, see-Cialdini, 2001). Social modeling is an established form of social influence (Bandura, 1977) that has been employed to promote pro-environmental behavior (e.g., Burn, 1991; Hopper \& Nielsen, 1991; Winett, Leckliter, Chinn, Stahl, \& Love, 1985). Indeed, meta-analytic evidence suggests that social modeling is one of the most effective means of promoting pro-environmental action (Osbaldiston \& Schott, 2012).

Little work has examined either the psychological processes through which modeling influences pro-environmental behavior or the role that the model's status or group membership plays. To address these questions we draw on three psychological constructs that meta-analytic evidence suggests are central to explanations of collective action: efficacy, injustice, and identity (Van Zomeren et al., 2008). Research shows that people are more likely to act when they perceive themselves, or their group, as having the efficacy to improve things. In addition, moral judgments of injustice also act as a positive predictor 
of collective action. As in other areas of human affairs (see Tyler, Boeckmann, Smith, \& Huo, 1997), it seems that moral concerns about what is fair and just are important in motivating collective action. Finally, perceiving oneself as a member of a group whose identity includes particular content and norms (e.g., environmentalist) is key to overcoming barriers of self-interest that characterize collective action problems such as climate change (Stúrmer \& Simon, 2004). Likewise, moral judgments of fairness, perceptions of efficacy, and notions of identity have also been shown to be important predictors of individual or "personal" pro-environmental behavior (Bamberg \& Möser, 2007; Hines et al., 1987; Whitmarsh \& O'Neill, 2010). As such, these three constructs are plausible candidates for clarifying the psychological processes that underpin social modeling effects.

\section{Potentially beneficial biases and possible psychological processes}

The worst effects of climate change affect members of groups that are both spatially and temporally distant. While discounting the interests of outgroup members (Hewstone, Rubin, \& Willis, 2002; Tajfel \& Turner, 1979) is one key psychological barrier to proenvironmental action (Markowitz \& Shariff, 2012), such ingroup bias can be employed in the service of pro-environmental goals by focusing on the influence exerted by ingroup (vs. outgroup) social models. For example, research in social psychology has demonstrated that social influence can vary as a function of group membership, with individuals tending to be more influenced by members of their own (in) groups (Abrams, Wetherell, Cochrane, Hogg, \& Turner, 1990; Turner, 1991). Classic social influence effects (e.g., Asch, 1955; Sherif, 1936) do not occur when the source of influence is an outgroup member (Abrams et al., 1990). As such, ene might expect that-ingroup social models might prove more effective than their outgroup counterparts in influencing pro-environmental perceptions, motivation, and action. If so, what can be a harmful bias when considering the negative outcomes of climate change might engender pro-environmental action through group-based social influence processes (for other pro-environmental effects of identity processes, see Rabinovich, Morton, Postmes, \& Verplanken, 2011).

Modeling support for collective action from other group members can lead to greater willingness to take action through increasing perceptions of efficacy and injustice (Van Zomeren, Spears, Fischer, \& Leach, 2004). Indeed, one of the most widely cited barriers to pro-environmental behavior change is the perceived lack of action by others and associated perceptions of inefficacy (Lorenzoni, Nicholson-Cole, \& Whitmarsh, 2007). Therefore, one might expect ingroup (vs. outgroup) social models to indirectly increase proenvironmental action tendencies by increasing perceptions of collective efficacy. In addition, on moral grounds it seems that if members of one's ingroup (vs. outgroup) are taking action then, all else being equal, it seems fairer that one should also contribute, even in circumstances when some members of the group are not acting (Tyler \& Dawes, 1993). Put simply, moral notions of what is fair and just are, to some degree, dependent on the actions of others (Haidt, 2001). It is also possible that ingroup social models may increase action tendencies through the perception of group norms (see Abrams et al., 
1990), leading to increased action in line with group norms (Jetten \& Spears, 1996). Therefore, as well as acting as a barrier, we argue that ingroup bias may also offer a potential means for engendering pro-environmental action (see also, Markowitz \& Shariff, 2012).

Social status is another important feature of social cognition (Fiske et al., 2007; Insel \& Fernald, 2004). Indeed, people seem particularly accurate in perceiving their own and others' social status (Anderson, John, Keltner, \& Kring, 2001). Models of social cognition suggest that status is a marker of competence (Fiske et al., 2007). As such, one might expect high (vs. low) status social models to have greater influence on people's motivations and actions (Henrich \& Gil-White, 2001; Markowitz \& Shariff, 2012; Sweetman, Spears, Livingstone, \& Manstead, 2013). In the present case, high status models may inspire people to believe that they, and others, have the efficacy to conduct pro-environmental actions and that such behavior is more normative of the group - as high status, or leading, members tend to be perceived as more prototypical of the group (Hogg, 2001). On the other hand, low (vs. high) status models may increase perceptions of collective efficacy. It is possible that one's perception of the collective efficacy to undertake proenvironmental action may be enhanced if "even" low status people, who are perceived as low in competence (Fiske et al., 2007), are seen as having the ability to act.

In addition, the status of models may influence moral judgments concerning the fairness of performing particular pro-environmental actions. It seems that, on grounds of justice, the most disadvantaged in society should not bear a disproportionate responsibility for tackling collective problems (Rawls, 1971). Therefore, pro-environmental actions carried out by low status models may make it seem only fair that others should also take action. On the other hand, seeing high status models do their "fair share" of action may also make it seem fairer for one to act (see Fehr, Yam, \& Dang, 2015). Taken together, if the group membership account of social influence is correct, then one would expect any indirect effects of the model's social status to be enhanced when the model also shares one's group membership.

\section{The present research}

Across three experiments, we employ an established psychological model of collective action - including perceptions of efficacy, moral judgments of fairness, and measures of pro-environmental social identity - in order to test the indirect effects of the status and group membership of social models on willingness to engage in pro-environmental action. In line with the group-basis of social influence account, we test whether the indirect effects of social model status are conditional on group membership (see Fig. 1 for a conceptual model). While personal pro-environmental actions (e.g., recycling, water conservation, sustainable transportation) are relatively malleable and can facilitate necessary reductions in carbon emissions (Dietz, Gardner, Gilligan, Stern, \& Vandenbergh, 2009), climate scientists have recently argued that only political action, aimed at radical institutional change, can avert climate catastrophe (Anderson, 2013). Therefore, we test whether 


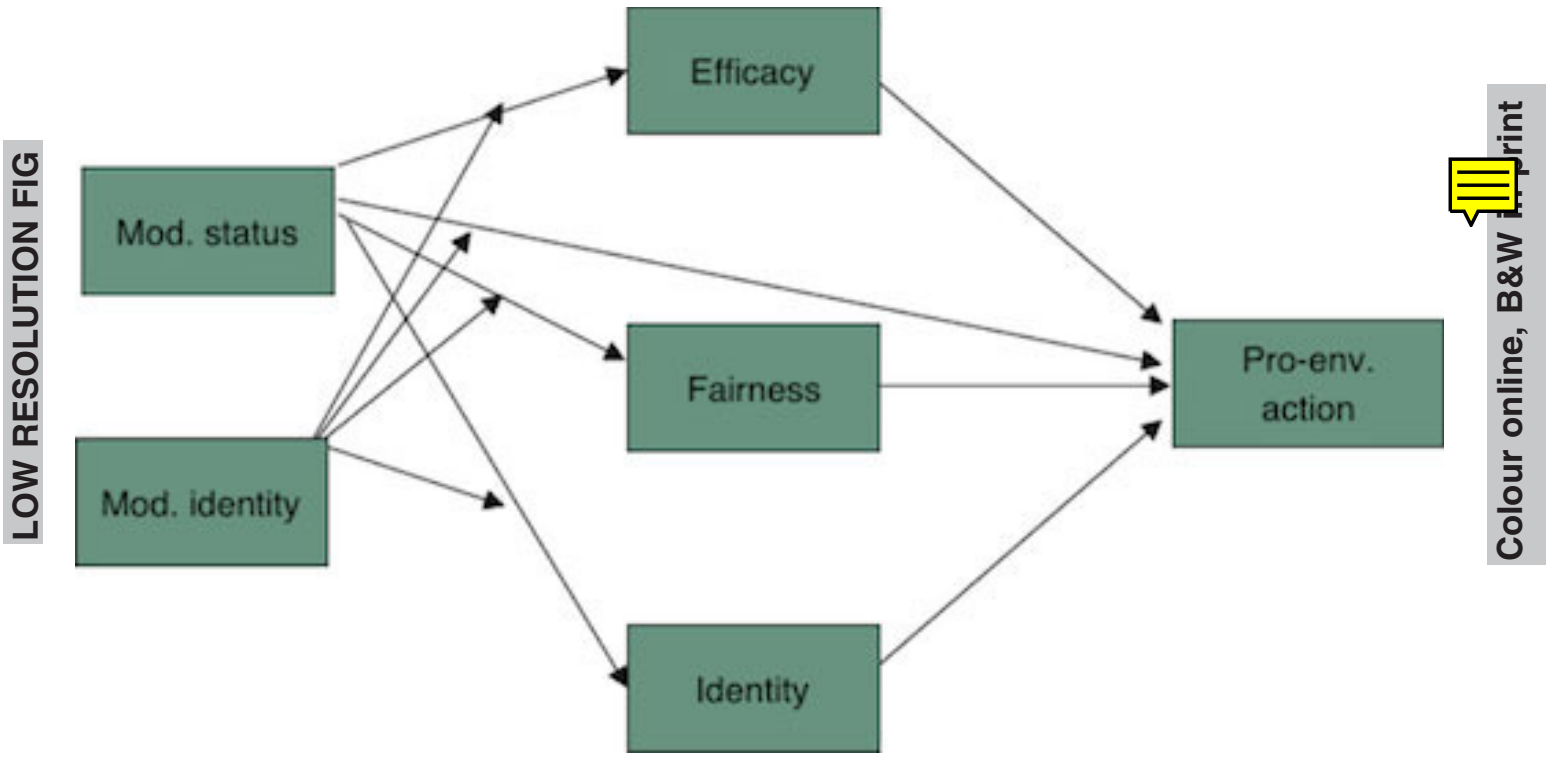

Fig. 1. Conceptual model: Direct and indirect effects of model (Mod.) status on willingness to take pro- 8 environmental (Pro-env.) action (through efficacy, fairness, and pro-environmental identity) as a function of model (Mod.) identity.

our psychological model can simultaneously account for willingness to engage in both personal and political pro-environmental action.

\subsection{Experiment 1: Testing for a conditional indirect effect of model status in a student sample}

\subsubsection{Participants, design, and procedure}

Participants were 129 British undergraduate students (117 women and 12 men; age: $M=19.27, S D=2.11$ ) who received course credit for participation. Participants were randomly allocated to one condition in a 2 (model status: high vs. low) $\times 2$ (model identity: ingroup vs. outgroup) between-subjects design. After being informed that the study was examining attitudes toward climate change, participants read a fictitious news article documenting the climate change actions undertaken by a social model. For example, in the high status, ingroup, condition participants read that:

Recently the CBI (Confederation of British Industry - a body representing British business) has introduced a climate change scheme whereby CEOs and other well-paid British business executives will pay $15 \%$ of their annual salaries to the CBI action on climate change project. The project has received broad support from CBI members. Importantly, this project invests in developing technologies and services (e.g., renew- 
able energy technology, energy efficiency projects, environmental management services) that are vital to tackling climate change.

In the low status condition, the model employed was homeless people paying $15 \%$ of their earnings through a scheme initiated by "The Big Issue UK (a street newspaper sold by homeless individuals in Britain)." In the outgroup condition, the high status (US chamber of commerce) and low status (The Big Issue USA) models were American. After participants read about the model's actions, they completed manipulation checks and, then, the measures of interest.

\subsubsection{Measures ${ }^{1}$}

4.1.2.1. Manipulation checks: To test the validity of our manipulation, we checked the perceived status of the model by asking participants to rate the status of the group taking action on a scale from 1 (low status) to 3 (high status). Participants were also asked to report the nationality of the group taking action.

4.1.2.2. Moral judgments: Participants rated each of the 14 personal and political actions listed below ( $\alpha=0.71$ and 0.86 , for personal and political behaviors, respectively) as to, "how fair it would be for you to take each one" on a scale from 1 (not at all fair) to 7 (extremely fair).

4.1.2.3. Pro-environmental social identity: Participants rated each of the 14 actions ( $\alpha=0.71$ and 0.73 , for personal and political behaviors, respectively) as to: "how 'British' (i.e., characteristic of British people) you consider each one to be" on a scale from 1 (not at all British) to 7 (extremely British).

4.1.2.4. Collective efficacy: Participants rated each action $(\alpha=0.85$ and 0.88 , for personal and political behaviors, respectively) as to: "how able British people are in general to perform each action" on a scale from 1 (not at all able) to 7 (extremely able).

4.1.2.5. Personal pro-environmental action: Participants rated how willing they were undertake nine behaviors $(\alpha=0.67)$ taken from Whitmarsh and O'Neill (2010) _ “turn on lights you're not using," "drive economically," "walk, cycle or take public transport for short journeys," "use an alternative to travelling," "cut down on the amount you fly," "eat food which is locally grown or in season," "avoid eating meat," "recycle," "turn off the tap when you brush your teeth" — on a scale from 1 (not at all willing) to 7 (very willing).

4.1.2.6. Political pro-environmental action: The political action items were derived from Van Zomeren et al. (2004): "write to your MP about climate change," "take part in a protest about climate change," "donate money to a campaign group on climate change," "do something together with fellow students to address climate change," and "join a campaign group to tackle climate change" $(\alpha=0.90)$. Again, participants rated these behaviors on a scale from 1 (not at all willing) to 7 (very willing). 


\subsection{Results and discussion}

\subsubsection{Manipulation checks}

There was a significant association between the manipulation of model status and the perceived status of the model, $\chi_{(2)}^{2}=57.76, p<.001$. As expected, a greater than chance proportion of those in the high status model condition perceived the model as having high status (57\% vs. $0 \%$ for perceived low status), $z=3.40, p<.001$. Similarly, a greater than chance proportion of those who the status model perceived the model as having low status $(56 \%$ vs. $9 \%$ for perceived high status), $z=4.10, p<.001$. The reported nationality of the model was contingent on model identity, $\chi_{(2)}^{2}=75.29, p<.001$. As expected, a greater than chance proportion (79\%) of those in the model outgroup (American) condition perceived the model as American (vs. 13\% and $8 \%$ who reported that the model was British or that they did not know, respectively), $z=4.80, p<.001$. Likewise, a greater than chance proportion (75\%) of those in the model ingroup (British) condition perceived the model as British (vs. 5\% and 20\% who reported that the model was American or that they did not know, respectively), $z=3.62, p<.001$. Taken together, these findings suggest that we were successful in manipulating the perceived status and group identity of the social model.

Means, standard deviations, and bivariate correlations between all continuous variables in the models are reported in Table 1. As predicted, with the exception of the association between pro-environmental identity and political action, all the mediators are significantly and positively associated with the-willingness to perform the corresponding (personal vs. political) pro-environmental behavior $(r \mathrm{~s}>.2, p \mathrm{~s}<.05)$.

\subsubsection{Moderated mediation analysis}

Using the PROCESS for SPSS macro (Hayes, 2013), we estimated the conditional indirect effect of model social status on willingness to take personal and political proenvironmental action through our measures of efficacy, fairness, and pro-environmental identity:

Table 1

Correlations among and descriptive statistics for key study variables (esperiment 1)

\begin{tabular}{|c|c|c|c|c|c|c|c|c|c|}
\hline & $M(S D)$ & 1 & 2 & 3 & 4 & 5 & 6 & 7 & 8 \\
\hline 1. Efficacy (personal) & $5.93(0.89)$ & & $0.47 * * *$ & 0.161 & $0.45 * * *$ & $0.77 * * *$ & $0.24 * *$ & $0.28 * *$ & 0.17 \\
\hline 2. Fairness (personal) & $5.73(0.69)$ & & & 0.067 & $0.68 * * *$ & $0.37 * * *$ & $0.50 * * *$ & 0.07 & $0.32 * * *$ \\
\hline 3. Identity (personal) & $4.09(0.80)$ & & & & $0.25 * *$ & 0.15 & -0.037 & $0.51 * * *$ & 0.11 \\
\hline 4. Behavior $_{(\text {personal })}$ & $5.55(.73)$ & & & & & $0.37 * * *$ & $0.44 * * *$ & $0.18 *$ & $0.47 * * *$ \\
\hline 5. Efficacy (political) & $5.37(1.29)$ & & & & & & $0.27 * *$ & $0.37 * * *$ & $0.20 *$ \\
\hline 6. Fairness (political) & $4.58(1.23)$ & & & & & & & 0.12 & $0.51 * * *$ \\
\hline 7. Identity (political) & $4.03(1.07)$ & & & & & & & & 0.10 \\
\hline 8. Behavior $_{(\text {political })}$ & $2.97(1.37)$ & & & & & & & & \\
\hline
\end{tabular}




$$
\begin{aligned}
& M_{1 \text { (efficacy) }}={ }^{i} M_{1 \text { (constant })}+a_{1} X_{1 \text { (model status })}+a_{2} X_{2 \text { (model identity })}+a_{3} X_{1} X_{2}+{ }^{\mathrm{e}} M_{1} \\
& M_{2 \text { (fairness) }}={ }^{i} M_{2 \text { (constant) }}+a_{4} X_{1 \text { (model status) }}+a_{5} X_{2 \text { (model identity) }}+a_{6} X_{1} X_{2}+{ }^{\mathrm{e}} M_{2} \\
& M_{3 \text { (pro-environmental identity) }}={ }^{i} M_{3 \text { (constant) }}+a_{7} X_{1 \text { (model status) }}+a_{8} X_{2 \text { (model identity) }} \\
& +a_{9} X_{1} X_{2}+{ }^{\mathrm{e}} M_{3} \\
& Y_{(\text {pro-environmental action })}={ }^{i} Y_{(\text {constant })}+c_{1}^{\prime} X_{1 \text { (model status })}+c_{2}^{\prime} X_{2(\text { model identity })}+c_{3}^{\prime} X_{1} X_{2} \\
& +b_{1} M_{1 \text { (efficacy) }}+b_{2} M_{2 \text { (fairness) }}+b_{3} M_{3 \text { (pro-environmental identity) }} \\
& +{ }^{\mathrm{e}} y
\end{aligned}
$$

where ${ }^{i} M$ and ${ }^{i} Y$ are intercept or constant terms and ${ }^{\mathrm{e}} M$ and ${ }^{\mathrm{e}} y$ are regression residuals. The coefficients $a_{1,2,4,5,7,8}$ and $b_{1-3}$ are then used to assess the presence of the indirect

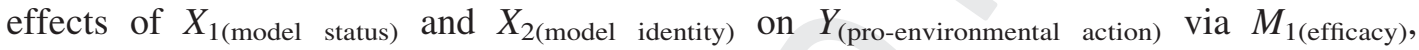

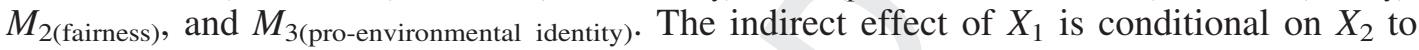
the extent that the interaction coefficients $a_{3,6,9}$ depart from zero. Coefficient $c^{\prime}{ }_{1}$ and $c^{\prime}{ }_{2}$ represent the direct effects of $X_{1}$ and $X_{2}$ with the direct effect of $X_{1}$ being conditional on $X_{2}$ to the extent that the interaction coefficient $c_{3}^{\prime}$ departs from zero. The coefficients in Equations (1-4) were estimated using ordinary least-squares regression and represent a full test of our conceptual model (see Fig. 1).

4.2.2.1. Personal pro-environmental action: As can be seen in Table 2 (Top) being exposed to a high (vs. low) status model decreased the extent to which British people were seen to possess the efficacy to carry out personal pro-environmental actions, and decreased judgments of the fairness of such actions. Put differently, we find evidence for the notion that the actions of low (vs. high) status models aimed at tackling climate change can serve to increase perceptions of collective efficacy and make it seem fairer to undertake action oneself. Model status was not significantly associated with perceptions of pro-environmental British identity. It seems that the high status of a social model is not, by itself, enough to shape group norms. We speculate that businesspersons might not be perceived as legitimate societal leaders and as such our high status model may not elicit the kind of leadership processes that can influence the content and norms associated with collective identity (Hogg, 2001). However, as predicted, measures of pro-environmental British identity, fairness, and efficacy were all positively associated with willingness to perform personal pro-environmental behavior. Contrary to group accounts of social influence (e.g., Turner, 1991), the model's group identity was not associated with any of the mediators and the direct effects of social model identity and status were not statistically significant.

As indicated by the interaction term $\left(X_{1} \times X_{2}\right)$ in Table 2, model group identity did not significantly moderate the effect of model status on any of the mediators. Furthermore, there was no evidence that the direct effect of model status was moderated by the 


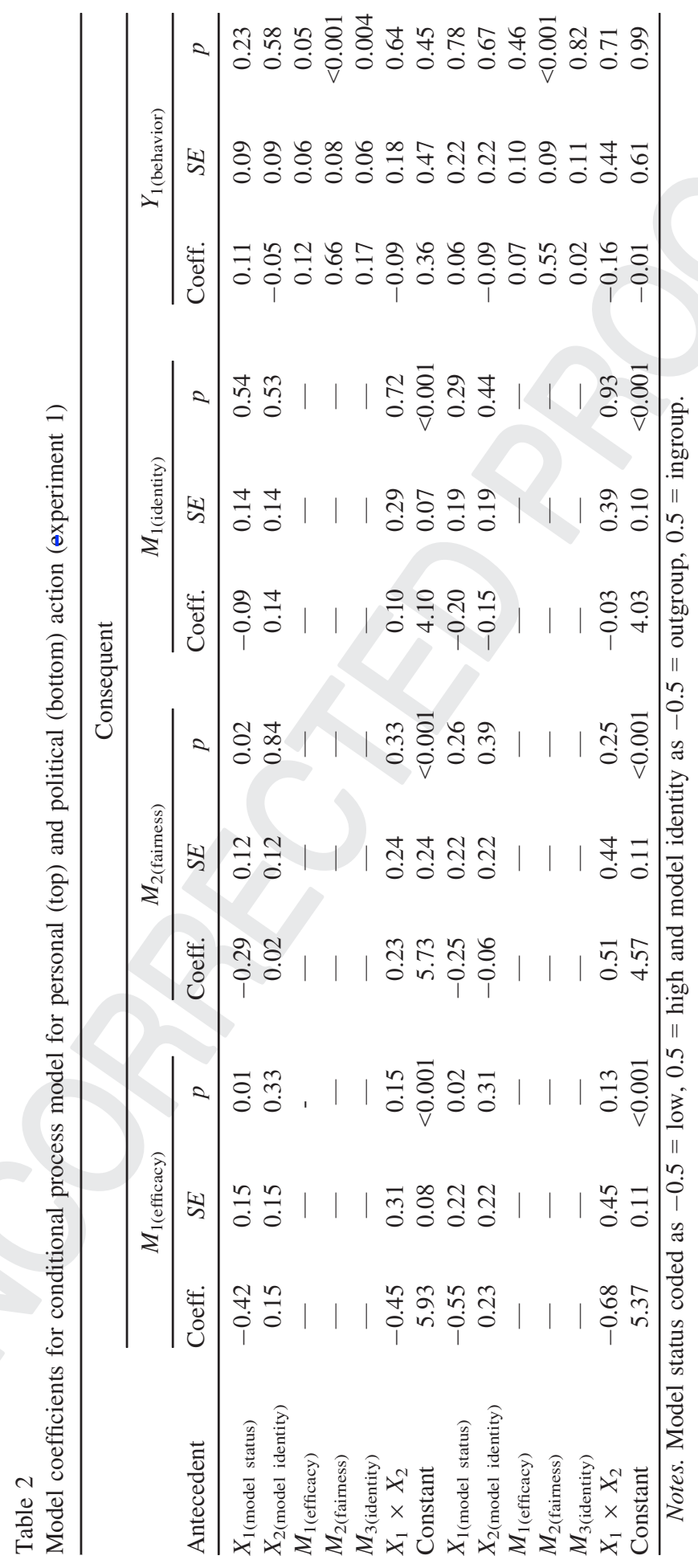


group membership of the model. This is evidence that the effect of model status on willingness to take personal pro-environmental action is not moderated by the group membership of the model. However, it is possible that an indirect effect may be moderated in the absence of evidence that a particular path is moderated (see Hayes, 2013). In order to conduct a formal test of whether indirect effects were moderated, we used PROCESS for SPSS macro with 5,000 bootstrap samples to estimate the conditional indirect effect of model status on willingness to take pro-environmental action through our mediators. For example, the conditional indirect of model status through moral judgments of fairness is quantified as $\left(a_{1}+a_{4} X_{2}\right) b_{2}$ where $a_{1}$ is the path model status $\rightarrow$ fairness, $a_{4}$ is the path model status*model group identity $\rightarrow$ fairness, $X_{2}$ is model group identity, and $b_{2}$ is the path fairness $\rightarrow$ willingness to take pro-environmental action.

A bias-corrected bootstrap-confidence interval (CI) revealed a significant negative indirect effect of model social status on willingness to perform personal pro-environmental action through moral judgments of the fairness of the actions (point estimate $=-0.27$, $95 \%$ percentile CI -0.51 to -0.06 ) in the outgroup, but not in the ingroup condition (point estimate $=-0.11,95 \%$ percentile CI -0.35 to 0.09 ). In other words, being exposed to a low (vs. high) status model increases the willingness to take personal pro-environmental action through increasing the perceived fairness of taking such action. But contrary to the group influence account, this indirect effect is only statistically significant when participants are presented with an outgroup (vs. ingroup) model. However, a bootstrap CI for the difference between conditional indirect effects, quantified as $a_{4} b_{2}\left(X_{2 \text { (ingroup) }}-X_{2 \text { (outgroup) }}\right.$ ), was not significant (point estimate $=0.15,95 \%$ percentile $\mathrm{CI}-0.13$ to 0.48 ). This means that the indirect effects of status through judgments of fairness do not differ statistically as a function of the model's group membership. The indirect effects of model status through perceptions of efficacy (point estimates $=-0.08,95 \%$ percentile CI -0.25 to 0.01 and $-0.02,95 \%$ percentile CI -0.14 to 0.02 , in the outgroup and ingroup conditions, respectively) and pro-environmental identity (point estimates $=-0.02,95 \%$ percentile $\mathrm{CI}-0.12$ to 0.04 and $-0.01,95 \%$ percentile $\mathrm{CI}-0.08$ to 0.06 in the outgroup and ingroup conditions, respectively) were also not statistically significant.

The indirect effects of model identity through judgments of fairness (point estimates $=-0.06,95 \%$ percentile $\mathrm{CI}-0.28$ to 0.14 and $0.09,95 \%$ percentile $\mathrm{CI}-0.13$ to 0.33 , for low and high status conditions, respectively), perceptions of efficacy (point estimates $=-0.01,95 \%$ percentile $\mathrm{CI}-0.10$ to 0.03 and $0.04,95 \%$ percentile $\mathrm{CI}-0.01$ to 0.20 , for low and high status conditions, respectively), and perceived pro-environmental identity (point estimates $=-0.02,95 \%$ percentile $\mathrm{CI}-0.12$ to 0.04 and -0.01 , $95 \%$ percentile $\mathrm{CI}-0.08$ to 0.07 , for low and high status conditions, respectively) were also not statistically significant.

Our analyses suggest that judgments of the fairness and efficacy of pro-environmental actions and the degree to which they are reflective of collective identity are all unique predictors of the willingness to engage in pro-environmental action. Contrary to the group-basis of influence account we find some limited evidence that outgroup social models with low (vs. high) status may increase willingness to take pro-environmental action through making such action seem fairer. 
4.2.2.2. Political pro-environmental action: As can be seen in Table 2 (Bottom), once again being exposed to a high (vs. low) status model decreased perceptions of possessing the collective efficacy to carry out pro-environmental actions. Model status was not significantly associated with judgments of pro-environmental social identity or the fairness of political actions. In contrast to personal actions, measures of pro-environmental social identity and collective efficacy did not predict willingness to take political action. However, moral judgments of the fairness of political action did predict political action tendencies. Again, we found no association between the model's group identity and any of our mediators and the direct effects of group identity and social model status were not statistically significant.

Once again, the model group identity did not significantly moderate the effect of model status on any of the mediators and there was no evidence that the direct effect of model status was moderated by the group membership. A bias-corrected bootstrap-confidence interval revealed that the indirect effects of model status through moral judgments of fairness (point estimates $=-0.27,95 \%$ percentile $\mathrm{CI}-0.66$ to 0.05 and $0.00,95 \%$ percentile CI -0.34 to 0.33 , in the outgroup and ingroup conditions, respectively), perceptions of efficacy (point estimates $=-0.06,95 \%$ percentile $\mathrm{CI}-0.26$ to 0.09 and $-0.01,95 \%$ percentile CI -0.16 to 0.03 , in the outgroup and ingroup conditions, respectively), and proenvironmental identity (point estimates $=-0.00,95 \%$ percentile CI -0.10 to 0.04 and $-0.01,95 \%$ percentile $\mathrm{CI}-0.13$ to 0.04 in the outgroup and ingroup conditions, respectively) were not statistically significant.

The indirect effects of model identity through judgments of fairness (point estimates $=-0.03,95 \%$ percentile $\mathrm{CI}-0.36$ to 0.27 and $0.24,95 \%$ percentile CI -0.10 to 0.63 , for low and high status conditions, respectively), perceptions of efficacy (point estimate $=-0.01,95 \%$ percentile $\mathrm{CI}-0.14$ to 0.04 and $0.04,95 \%$ percentile $\mathrm{CI}-0.04$ to 0.23 , for low and high status conditions, respectively), and perceived pro-environmental identity (point estimate $=-0.00,95 \%$ percentile $\mathrm{CI}-0.09$ to 0.04 and $-0.00,95 \%$ percentile CI -0.11 to 0.04 , for low and high status conditions, respectively) were also not statistically significant.

4.2.2.3. Additional analyses ${ }^{2}$ : Due to the high number (23\%) of participants who did not report the correct group membership of the social model we carried out the above analyses with only those that gave a correct response. Results for personal action no longer revealed a significant indirect effect of model status through moral judgments of fairness (point estimates $=-0.16,95 \%$ percentile CI -0.40 to 0.07 and $-0.14,95 \%$ percentile CI -0.41 to 0.07 , in the outgroup and ingroup conditions, respectively). High (vs. low) status model was still associated with a decrease in perceived collective efficacy, $b=-0.40, t(94)=-2.16, p=.03$. However, perceptions of collective efficacy no longer uniquely predicted personal action tendencies, $b=0.07, t(91)=1.22, p=.22$. High (vs. low) status model was now only marginally associated with a decrease in fairness judgments, $b=-0.23, t(94)=-1.71, p=.09$. However, moral judgments and pro-environmental social identity continued to uniquely predict personal action tendencies, $b=0.66$, $t(91)=8.09, p<.001$ and $b=0.15, t(91)=2.53, p=.013$, respectively. There were no 
other significant effects in this new model. The results for political action did not change with a high (vs. low) status model still being associated with a decrease in perceived collective efficacy, $b=-0.56, t(94)=-2.16, p=.03$. And moral judgments of fairness continued to uniquely predict willingness to take political action, $b=0.53, t(91)=5.26$, $p<.001$. These additional analyses cast some doubt on the robustness of our indirect effect of model status through moral judgments.

\subsection{Experiment 2: Testing for a conditional indirect effect of model status in a non-student sample}

The results of Experiment 1 strongly indicate that moral judgments of an action's fairness are an important predictor of willingness to take pro-environmental action. The results of our additional analyses cast some doubt on the potential for the status and group membership of social models to influence pro-environmental action through moral judgments, perceptions of efficacy, and pro-environmental social identity. Therefore, we aimed to replicate our initial findings in a larger, non-student sample. This allows us to address the limited statistical power in Experiment 1 (see Fritz \& MacKinnon, 2007), which is of particular concern when considering the results of our additional analyses. Further, it allows us to explore whether similar effects occur in a more representative, non-student sample (see Sears, 1986; but see Anderson, Lindsay, \& Bushman, 1999).

\subsubsection{Participants, design, and procedure}

Participants were 333 American citizens (212 women and 117 men; age: $M=32.10$, $S D=11.53 ; 60 \%$ possessed a college degree) who were recruited from an online crowdsourcing platform and received $\$ 1.82$ for their participation (US minimum wage for a 10-15 min study). We employed the same design and procedure as in Experiment 1.

\subsubsection{Measures}

We employed the same measures as in Experiment 1 with three differences. First, we changed relevant items and corresponding anchors from "British" to "American." Second, we changed two of the political action items: "write to your [MP] Representative or Senator about climate change" and "do something together with [fellow students] others to address climate change." In addition, we checked the social model's perceived status by asking participants to rate the status of the group taking action on a scale from 1 (very high status) to 7 (very low high status). We reverse coded for ease of interpretation.

Our measures of moral judgments of the fairness of action $(\alpha=0.90$ and 0.92 , for personal and political action, respectively), collective efficacy $(\alpha=0.93$ and 0.93 , for personal and political action, respectively), pro-environmental social identity $(\alpha=0.92$ and 0.91 , for personal and political action, respectively), and willingness to take pro-environmental action ( $\alpha=0.88$ and 0.94 , for personal and political action, respectively) all showed excellent reliability. 


\subsection{Results and discussion}

\subsubsection{Manipulation checks}

An ANOVA with model identity and status as between-subjects factors and perceived model status as the dependent variable revealed participants in the high status condition $(M=4.65, S D=1.19)$ saw the social model as higher in status than their counterparts in the low status condition $(M=3.08, S D=2.42), F(1,329)=56.29, p<.001, \eta_{p}^{2}=0.15$. Unexpectedly, there was a statistically significant effect of social model group membership on perceptions of status with participants rating the British (outgroup) models as higher in status $(M=4.08, S D=2.09)$ than their American (ingroup) counterparts $(M=3.64, S D=2.03)$, although the magnitude of this effect was extremely small, $F(1$, $329)=4.25, p=.04, \eta_{p}^{2}=0.01$. The reported nationality of the model was contingent on model identity, $\chi_{(2)}^{2}=289.37, p<.001$. As expected, a greater than chance proportion (93\%) of those in the model ingroup condition perceived the model as American (vs. 2\% and $5 \%$ who reported that the model was British or that they did not know, respectively), $z=8.29, p<.001$. Likewise, a greater than chance proportion (95\%) of those in the model outgroup condition perceived the model as British (vs. $3 \%$ and $2 \%$ who reported that the model was American or that they didn't know, respectively), $z=8.65, p<.001$. Taken together, these findings suggest that we were successful in manipulating the perceived status and group identity of the social model.

Means, standard deviations, and bivariate correlations between all continuous variables in the models are reported in Table 3. As predicted, all the mediators are significantly and positively associated with the willingness to perform the corresponding (personal vs. political) pro-environmental behavior $(r s>.26, p s<.001)$.

\subsubsection{Moderated mediation analysis}

Again, we estimated our conceptual model (see Fig. 1) using ordinary least-squares regression.

Table 3

Correlations among and descriptive statistics for key study variables (experiment 2)

\begin{tabular}{|c|c|c|c|c|c|c|c|c|}
\hline & $M(S D) \quad 1$ & 2 & 3 & 4 & 5 & 6 & 7 & 8 \\
\hline 1. Efficacy (personal) & $5.37(1.31)$ & $0.47 * * *$ & $0.25^{* * *}$ & $0.57 * * *$ & $0.88 * * *$ & $0.35 * * *$ & $0.30 * * *$ & $0.28 * * *$ \\
\hline 2. Fairness (personal) & $5.56(1.24)$ & & $0.28 * * *$ & $0.72 * * *$ & $0.48 * * *$ & $0.75 * * *$ & $0.37 * * *$ & $0.37 * * *$ \\
\hline 3. Identity(personal) & $4.08(1.26)$ & & & $0.34 * * *$ & $0.20 * * *$ & $0.27 * * *$ & $0.69 * * *$ & $0.28 * * *$ \\
\hline 4. Behavior $_{\text {(personal) }}$ & $5.32(1.26)$ & & & & $0.52 * * *$ & $0.58 * * *$ & $0.41 * * *$ & $0.56 * * *$ \\
\hline 5. Efficacy (political) & $5.32(1.44)$ & & & & & $0.40 * * *$ & $0.35 * * *$ & $0.35 * * *$ \\
\hline 6. Fairness (political) & $5.14(1.59)$ & & & & & & $0.42 * * *$ & $0.54 * * *$ \\
\hline 7. Identity (political) & $4.68(1.35)$ & & & & & & & $0.27 * * *$ \\
\hline 8. Behavior $_{\text {(political) }}$ & $3.79(1.91)$ & & & & & & & \\
\hline
\end{tabular}


4.4.2.1. Personal pro-environmental action: In contrast to our initial analyses of Experiment 1 model status did not have any significant association with perceptions of collective efficacy or moral judgments of fairness (see Table 4, Top). Indeed, neither model status nor group membership was statistically associated with any of our mediators. However, in keeping with the initial results of Experiment 1 our measures of fairness, perceived collective efficacy, and pro-environmental identity all uniquely predicted personal action tendencies. Again, the direct effects of group identity and social model status were not statistically significant and model group identity did not significantly moderate the effect of model status on any of the mediators. In addition, the direct effect of model status was not moderated by the group membership of the model.

A bias-corrected bootstrap-CI revealed a significant positive indirect effect of model status on willingness to perform personal pro-environmental action through perceptions of collective efficacy (point estimate $=0.09,95 \%$ percentile CI 0.01 to 0.24 ) in the outgroup but not in the ingroup condition (point estimate $=-0.00,95 \%$ percentile $\mathrm{CI}-0.11$ to 0.11). That is, being exposed to a high (vs. low) status model increases willingness to take personal action through increasing the perceived collective efficacy of the ingroup to take action. But contrary to the group influence account, this indirect effect is only statistically significant when participants are presented with an outgroup (vs. ingroup) model. However, a bootstrap CI for the difference between conditional indirect effects was not significant (point estimate $=-0.10$, 95\% percentile CI -0.29 to 0.03 ). This means that the conditional indirect effects of status through judgments of efficacy do not differ statistically as a function of the model's group membership.

Unlike the initial analyses of Experiment 1, the indirect effects of model status through moral judgments of fairness (point estimates $=-0.04,95 \%$ percentile CI -0.27 to 0.17 and $0.13,95 \%$ percentile CI -0.07 to 0.35 , in the outgroup and ingroup conditions, respectively) were not statistically significant. Indirect effects of status through pro-environmental identity (point estimates $=-0.02,95 \%$ percentile $\mathrm{CI}-0.08$ to 0.02 and 0.01 , $95 \%$ percentile $\mathrm{CI}-0.03$ to 0.07 in the outgroup and ingroup conditions, respectively) were also not statistically significant.

The indirect effect of model identity through judgments of fairness was significant and positive (point estimate $=0.20,95 \%$ percentile CI 0.01 to 0.44 ) in the high but not in the low status condition (point estimate $=-0.03$, 95\% percentile CI -0.21 to 0.27 ). Put simply, having an ingroup (vs. outgroup) model of high status increased action tendencies through making engaging in action seem fairer. However, a bootstrap CI for the difference between conditional indirect effects was not significant (point estimate $=-0.17$, $95 \%$ percentile $\mathrm{CI}-0.14$ to 0.50 ). There was also a significant positive indirect effect of model identity through perceptions of collective efficacy (point estimate $=0.11$, 95\% percentile CI 0.01 to 0.27 ) in the low but not in the high status condition (point estimate $=0.01,95 \%$ percentile CI -0.08 to 0.14 ). This suggests that having an ingroup (vs. outgroup) model of low status increased action tendencies through making increasing perceptions of collective efficacy. However, once again, a bootstrap CI for the difference between conditional indirect effects was not significant (point estimate $=-0.10,95 \%$ percentile CI -0.29 to 0.03 ). Finally, neither of the indirect effects of model identity 


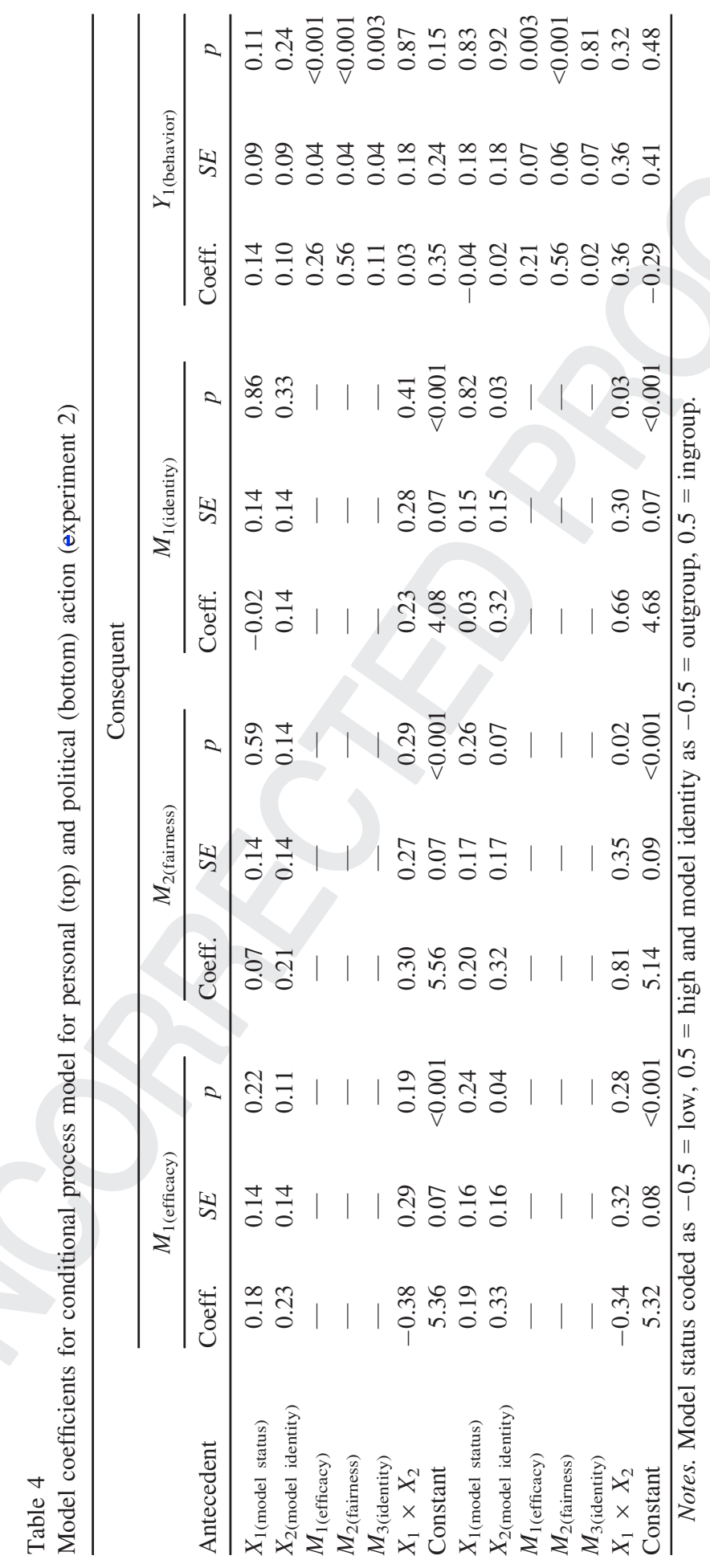


through perceived pro-environmental identity (point estimates $=0.00,95 \%$ percentile $\mathrm{CI}$ -0.04 to 0.06 and $0.03,95 \%$ percentile CI -0.005 to 0.10 , for low and high status conditions, respectively) were statistically significant.

4.4.2.2. Political pro-environmental action: As can be seen in Table 4 (Bottom), viewing an ingroup (vs. outgroup) model increased perceptions of the collective efficacy to carry out pro-environmental actions, the extent to which such actions were seen as characteristic of Americans, and (marginally) the fairness of such actions. These results offer support for the group influence account and extend the positive effects of ingroup action beyond perceptions of collective efficacy (Van Zomeren et al., 2004). In keeping with our findings for personal action in both the current study and Experiment 1, we find that perceptions of collective efficacy and moral judgments of the fairness of engaging in action predict action tendencies. However, pro-environmental social identity did not uniquely predict action tendencies. Again, the direct effects of group identity and social model status were not statistically significant.

In support of our conditional process account in Fig. 1, the effects of the model's monters on judgments of fairness and pro-environmental social identity were moderated by effect of model status through moral judgments of fairness (point estimate $=0.34,95 \%$ percentile CI 0.10 to 0.64 ) in the ingroup but not the outgroup condition (point estimate $=-0.12,95 \%$ percentile CI -0.41 to 0.16 ). In other words, high status social models increase political pro-environmental action through making engaging in such actions seem more moral, but only when the social model was an ingroup member. A bootstrap CI for the difference between conditional indirect effects was significant (point estimate $=0.45$, $95 \%$ percentile CI 0.09 to .90). This is evidence for our conceptual model and for the idea we may use ingroup bias and tendencies to be influenced by high status models in order to engender pro-environmental action(see Markowitz \& Shariff, 2012)

The indirect effects of model status through perceptions of efficacy (point estimates $=$ $.08,95 \%$ percentile $\mathrm{CI}-0.00$ to 0.21 and $0.00,95 \%$ percentile $\mathrm{CI}-0.10$ to 0.09 , for outgroup and ingroup conditions, respectively) and perceived pro-environmental identity (point estimates $=-0.01,95 \%$ percentile $\mathrm{CI}-0.09$ to 0.04 and $-0.00,95 \%$ percentile $\mathrm{CI}-0.05$ to 0.11 , for outgroup and ingroup conditions, respectively) were not statistically significant.

In addition, the indirect effect of model identity through perceptions of efficacy (point estimate $=0.10,95 \%$ percentile CI 0.01 to 0.29 ) was significant for low but not high status models $(0.03,95 \%$ percentile CI -0.04 to 0.16 , for low and high status conditions, respectively). However, a bootstrap CI for the difference between conditional indirect effects was not significant (point estimate $=-0.07,95 \%$ percentile CI -0.26 to 0.04 ). Finally, the indirect effects of model identity through perceived pro-environmental identity (point estimates $=-0.00,95 \%$ percentile $\mathrm{CI}-0.04$ to 0.04 and $0.01,95 \%$ percentile $\mathrm{CI}-0.09$ to 0.13 , for low and high status conditions, respectively) were not statistically significant.

We found evidence that high (vs. low) status social models increase political pro-environmental action through making engaging in such actions seem fairer, but only when the social model is an ingroup member. This is in line with group influenee aecounts that 
suggest ingroup membership is an important facilitator of social influence-(Abrams et al., 1990; e.g., Turner, 1991).

\subsection{Experiment 3: Testing for a conditional indirect effect of model status in a student sample with a more meaningful ingroup membership}

The results of Experiment 2 offer some support for our conceptual model. However, they are somewhat inconsistent with those of Experiment 1. We reasoned that the failure to support our conceptual model may be due to the limited statistical power in Experiment 1, the quality of data, and/or properties of student samples (see Sears, 1986). Related to the latter, we reasoned that a failure to support the group influence account might be due to the ingroup membership not being salient or meaningful enough in Experiment 1. Therefore, we carried out another replication but this time employed a more meaningful and salient ingroup membership for a student sample: student identity.

\subsubsection{Participants, design, and procedure}

Participants were 229 British students (205 women and 22 men; age: $M=19.48$, $S D=4.45$ ) who participated for course credit. We employed the same design and procedure as in Experiment 1 with one key difference. We employed the CBI and Big Issue UK social models as in Experiment 1 but this time participants in the high status (student) ingroup condition read that:

Recently Oxford University's Student Union has introduced a climate change scheme whereby the Union will pay $15 \%$ of its annual funding to the Oxford University action on climate change project. The project has received broad support from Oxford students. Importantly, this project invests in developing technologies and services (e.g., renewable energy technology, energy efficiency projects, environmental management services) that are vital to tackling climate change, and moves away (divests funds) from fossil fuels.

In the low status (student) ingroup condition, the social model employed was students from the University of Brighton, a relatively lower status British university.

\subsubsection{Measures}

We employed the same measures as in Experiment 1. Our measures of moral judgments of the fairness of action $(\alpha=0.67$ and 0.84 , for personal and political action, respectively), collective efficacy $(\alpha=0.79$ and 0.84 , for personal and political action, respectively), pro-environmental social identity $(\alpha=0.87$ and 0.85 , for personal and political action, respectively), and willingness to take pro-environmental action ( $\alpha=0.68$ and 0.88 , for personal and political action, respectively) all showed adequate reliability. 


\subsection{Results and discussion}

\subsubsection{Manipulation checks}

Participants in the high status condition $(M=4.62, S D=1.22)$ saw the social model as higher in status than those in the low status condition $(M=4.16, S D=1.73)$, $F(1,222)=5.63, p=.02, \eta_{p}^{2}=0.03$. There was no statistically significant effect of social model group membership on perceptions of status, $F(1,222)=1.70, p=.19, \eta_{p}^{2}=0.01$. However, there was an unexpected interaction between model status and group membership, $F(1,222)=4.75, p=.03, \eta_{p}^{2}=0.02$. Analyses revealed that the simple main effect of model status was only significant in the ingroup (student) condition, $F(1,222)=10.33$, $p=.001, \eta_{p}^{2}=0.05$; participants in the ingroup high status model condition $(M=4.97$, $S D=1.01)$ rated the status of the model as higher than their counterparts in the low status condition $(M=4.07, S D=1.15)$. In contrast, those in the outgroup high status condition $(M=4.28, S D=1.32)$ did not differ from their counterparts in the low status condition $(M=4.25, S D=2.17), F(1,222)=0.02, p=.89, \eta_{p}^{2}=0.000$. These findings suggest that on average we were successful in manipulating model status. However, it seems that this effect is driven by the perceived status difference between the student ingroup models. One explanation may be that British students are particularly unwilling to report the low status of homeless people (or the high status of business executives). This is in deep contrast to our non-student American sample and other representative American samples who have been shown to engage in extreme stereotyping of the homeless (Fiske et al., 2007). This may also shed light on the inconsistencies in social model effects across Experiment 1 and 2.

The reported group membership of the model was contingent on model identity, $\chi_{(2)}^{2}=166.15, p<.001$. As expected, a greater than chance proportion $(79 \%)$ of those in the model ingroup condition perceived the model as student (vs. $4 \%$ and $17 \%$ who reported that the model was not a student/student body or that they did not know, respectively), $z=6.69, p<.001$. Likewise, a greater than chance proportion $(80 \%)$ of those in the model outgroup (CEO and Big Issue) condition perceived the model correctly (vs. $2 \%$ and $18 \%$ who reported that the model was a student or that they did not know, respectively), $z=6.15, p<.001$. These findings suggest that we were successful in manipulating the perceived group identity of the social model.

Means, standard deviations, and bivariate correlations between all continuous variables in the models are reported in Table 5. As predicted, all the mediators are significantly and positively associated with the willingness to perform the corresponding (personal vs. political) pro-environmental behavior $(r s>.22$, $p s<.05)$.

\subsubsection{Moderated mediation analysis}

Again, we estimated our conceptual model (see Fig. 1) using ordinary least-squares regression.

4.6.2.1. Personal pro-environmental action: As in Experiment 2, model status did not have any significant association with perceptions of collective efficacy or moral judgments of fairness (see Table 6, Top). Again, neither model status nor group membership 
Table 5

Correlations among and descriptive statistics for key study variables (experiment 3)

\begin{tabular}{|c|c|c|c|c|c|c|c|c|c|}
\hline & $M(S D)$ & 1 & 2 & 3 & 4 & 5 & 6 & 7 & 8 \\
\hline 1. Efficacy $_{(\text {personal) }}$ & $5.62(0.80)$ & & $0.33 * * *$ & $0.27 * * *$ & $0.46 * * *$ & $0.49 * * *$ & $0.23 * * *$ & $-0.15^{*}$ & 0.07 \\
\hline 2. Fairness (personal) & $5.67(0.67)$ & & & $0.14 *$ & $0.56 * * *$ & $0.34 * * *$ & $0.59 * * *$ & -0.01 & $0.30 * * *$ \\
\hline 3. Identity (personal) & $4.50(1.14)$ & & & & $0.22 *$ & $0.18 * *$ & 0.09 & $0.19 * *$ & $0.21 * *$ \\
\hline 4. Behavior $_{(\text {personal) }}$ & $5.66(0.74)$ & & & & & $0.27 * * *$ & $0.40 * * *$ & 0.00 & $0.36^{* * *}$ \\
\hline 5. Efficacy (political) & $4.45(1.17)$ & & & & & & $0.46^{* * *}$ & $0.19 * *$ & $0.44 * * *$ \\
\hline 6. Fairness (political) & $4.82(1.13)$ & & & & & & & $0.18 * *$ & $0.58 * * *$ \\
\hline 7. Identity (political) & $3.49(1.28)$ & & & & & & & & $0.33 * * *$ \\
\hline 8. Behavior $_{\text {political })}$ & $3.40(1.40)$ & & & & & & & & \\
\hline
\end{tabular}

Notes. $* p<.05$.

$* * p<.01$.

$* * * p<.001$.

was statistically associated with any of our mediators. However, in keeping with the results of Experiment 1 and 2 our measures of fairness, perceived collective efficacy, and pro-environmental identity (marginally) all uniquely predicted personal action tendencies. In support of our conditional process account (see Fig. 1), and the political action findings from Experiment 2, the effects of the model's group membership on judgments of fairness were moderated by model status. Once again, a bias-corrected bootstrap-confidence interval revealed a positive indirect effect of model status through moral judgments of fairness (point estimate $=0.11,95 \%$ percentile CI 0.002 to 0.25 ) in the ingroup but not the outgroup condition (point estimate $=-0.05$, 95\% percentile CI -0.19 to 0.07 ). As for political action in Experiment 2, high status social models increased pro-environmental action tendencies through making engaging in such actions seem fairer, but only when the social model was an ingroup member. A bootstrap CI for the difference between conditional indirect effects was significant (point estimate $=0.17,95 \%$ percentile CI 0.004 to 0.37 ). This is evidence for our conceptual model that proposes the conditional indirect effects of model status on pro-environmental action. Model group identity did not significantly moderate the effect of model status on any of the mediators.

Again, the direct effects of group identity and social model status were not statistically significant. However, this time the direct effect of model status was moderated by the group membership of the model. Examination of the conditional direct effects indicated that the effect of model status was significant in the ingroup $(b=0.25, t(217)=2.31$, $p=.02)$, but not outgroup condition $(b=-0.06, t(217)=-0.52, p=.60)$. That is, high (vs. low) status social models increased pro-environmental action tendencies directly, but only when the social model is an ingroup member.

Unlike Experiment 2 bias-corrected bootstrap-CI revealed no significant positive indirect effect of model status through perceptions of collective efficacy (point estimates $=0.05,95 \%$ percentile $\mathrm{CI}-0.03$ to 0.14 and $0.03,95 \%$ percentile $\mathrm{CI}-0.05$ to 0.12 , in the outgroup and ingroup conditions, respectively) and pro-environmental identity (point estimates $=0.00,95 \%$ percentile $\mathrm{CI}-0.02$ to 0.04 and $-0.01,95 \%$ percentile CI -0.06 to 0.01 , in the outgroup and ingroup conditions, respectively). 


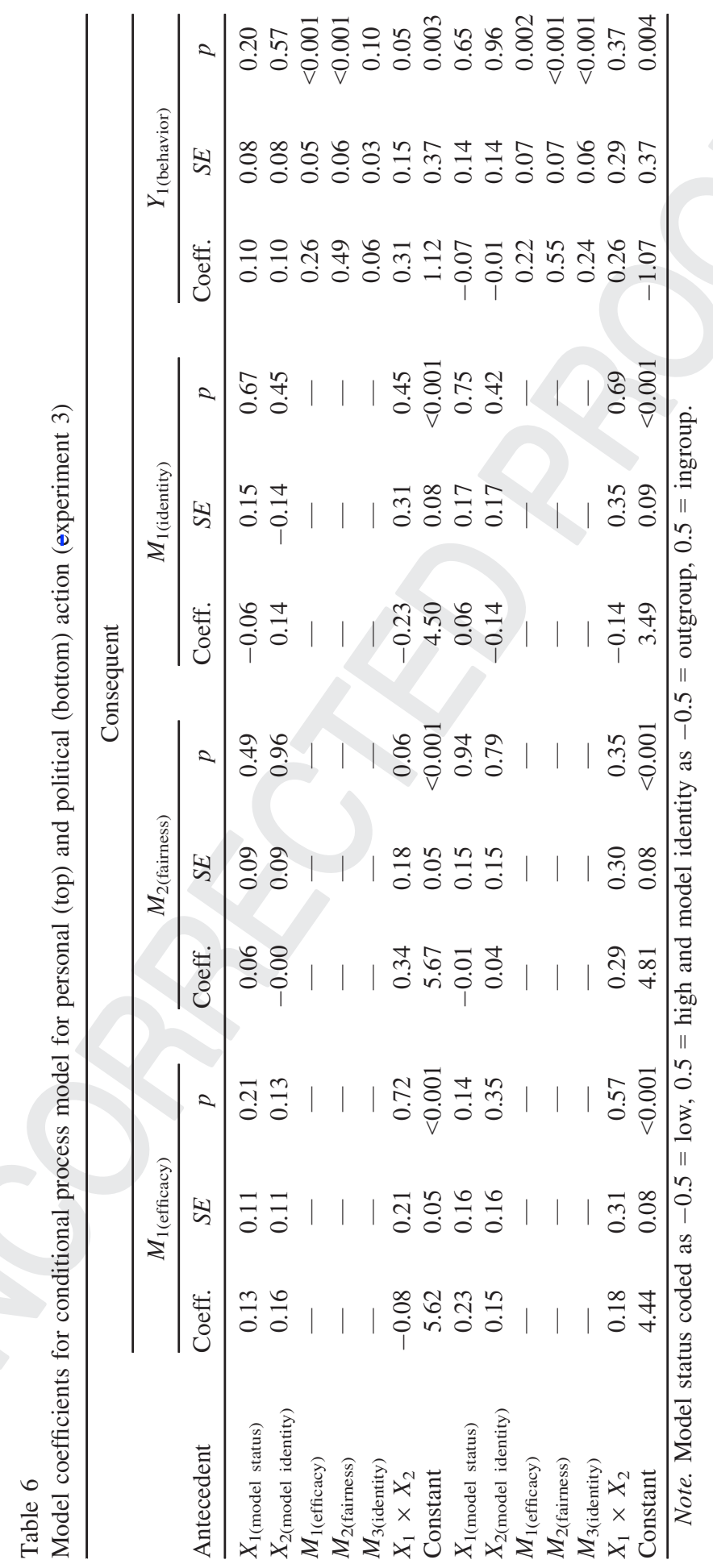


The indirect effects of model identity through judgments of fairness (point estimates $=-0.09,95 \%$ percentile $\mathrm{CI}-0.23$ to 0.04 and $0.08,95 \%$ percentile $\mathrm{CI}-0.03$ to 0.22 , for low and high status conditions, respectively), perceptions of efficacy (point estimates $=0.05,95 \%$ percentile $\mathrm{CI}-0.02$ to 0.15 and $0.03,95 \%$ percentile $\mathrm{CI}-0.04$ to 0.13 , for low and high status conditions, respectively), and perceived pro-environmental identity (point estimates $=-0.00,95 \%$ percentile $\mathrm{CI}-0.03$ to 0.02 and $-0.01,95 \%$ percentile CI -0.07 to 0.00 , for low and high status conditions, respectively) were also not statistically significant.

4.6.2.2. Political pro-environmental action: As can be seen in Table 6 (Bottom), neither model status, group membership, nor their interaction term were statistically associated with our mediators. Again, the direct effects of social model identity and status were not statistically significant. And the direct effect of model status was not moderated by model group membership. However, once again, our measures of fairness, perceived collective efficacy, and pro-environmental identity all uniquely predicted political action tendencies.

The indirect effects of model status through moral judgments of fairness (point estimates $=-0.09,95 \%$ percentile $\mathrm{CI}-0.35$ to 0.16 and $0.07,95 \%$ percentile $\mathrm{CI}-0.15$ to 0.29 , for outgroup and ingroup conditions, respectively), perceptions of efficacy (point estimates $=0.03,95 \%$ percentile $\mathrm{CI}-0.06$ to 0.14 and $0.07,95 \%$ percentile $\mathrm{CI}-0.01$ to 0.22 , for outgroup and ingroup conditions, respectively), and perceived pro-environmental identity (point estimates $=0.03,95 \%$ percentile $\mathrm{CI}-0.07$ to 0.16 and -0.00 , 95\% percentile $\mathrm{CI}-0.13$ to 0.13 , for outgroup and ingroup conditions, respectively) were not statistically significant.

In addition, the indirect effects of model group identity through moral judgments of fairness (point estimates $=-0.06$, $95 \%$ percentile $\mathrm{CI}-0.29$ to 0.18 and 0.10 , $95 \%$ percentile CI -0.14 to 0.34 , for outgroup and ingroup conditions, respectively), perceptions of efficacy (point estimates $=0.01,95 \%$ percentile CI -0.09 to 0.12 and 0.05 , $95 \%$ percentile CI -0.03 to 0.20 , for outgroup and ingroup conditions, respectively), and perceived pro-environmental identity (point estimates $=-0.02,95 \%$ percentile $\mathrm{CI}-0.15$ to 0.11 and $-0.05,95 \%$ percentile CI -0.18 to 0.05 , for outgroup and ingroup conditions, respectively) were also not statistically significant.

Our findings offer some further support for our conceptual model. Once again, we find that high (vs. low) status models engender pro-environmental action, albeit personal this time, through making such actions seem morally more just; but only when the model shares a meaningful ingroup membership. Indeed, we find evidence that this group-conditional influence of high status may also have a direct impact on action tendencies.

\section{General discussion}

Recent work has suggested that aspects of our social and moral cognition may be a significant barrier to engendering actions to tackle climate change (e.g., Markowitz \& Shariff, 2012). Here we report evidence that through group-based social influence 
(Abrams et al., 1990; Turner, 1991), and our moral sense of justice, it may be possible to employ these characteristics of the human mind to engender pro-environmental action (see also Feinberg \& Willer, 2013). Building on the efficacy of social modeling approaches to engender pro-environmental behavior change (see Osbaldiston \& Schott, 2012) we find evidence that high (vs. low) status models increase pro-environmental action, in part, through making such actions seem morally fairer to undertake. We find some evidence that this effect of high status models only occurs when they share a meaningful ingroup membership with the target of influence. Further, we find evidence that this group-based conditional influence of high status models may also have a direct impact on action tendencies. While the exact behaviors that are influenced may vary across student and non-student samples (see Sears, 1986), a focus on the "justice pathway" to action and the social-cognitive features of social models may offer a good opportunity for cognitive and behavioral scientists to integrate insights from basic research with those stemming from less controlled, applied efforts (see Osbaldiston \& Schott, 2012).

We found that moral judgments of the fairness of pro-environmental action were consistently the strongest predictor of willingness to engage in such action. While this predictive power is impressive in itself and adds more specificity to work that has shown more general environmental moral norms to be an important predictor of pro-environmental action (for a review, see Bamberg \& Möser, 2007), perhaps most exciting is the responsiveness of this moral pathway to the actions of high status members of one's ingroup. In general, this finding is in keeping with approaches that suggest moral judgments and norms are to some significant degree shaped by social influence processes (Darley, 1990; e.g., Haidt, 2001) and that those with high status (e.g.,-Henrich \& Gil-White, 2001; Markowitz \& Shariff, 2012; Sweetman et al., 2013) and ingroup membership (Abrams et al., 1990;-e.g., Turner, 1991) possess greater powers of social influence. Moreover, it points toward ways in which those with power and status may influence behavior through the development of "moral leadership" (see Fehr et al., 2015; Van Zant \& Moore, 2015).

Beyond simply framing climate change messages to appeal to moral values (Feinberg \& Willer, 2013; Markowitz \& Shariff, 2012) our findings go to the heart of deeper moral notions associate with "climate justice." In particular, our findings concern notions of climate justice within, rather than between, societies and groups. That is, our results suggest that those with power and status are in a particularly opportune position within societies and groups. On the one hand, their greater agency, influence, and resources mean they are able to have a greater impact on tackling climate change. At the same time, their high status also seems to convey on them a special role for shaping moral norms (see Keltner, Van Kleef, Chen, \& Kraus, 2008). While it is easy to use the classic problems of collective action as a reason for inaction, our data suggests that, rather than free-riding, people may respond to the pro-environmental actions of high status members of their group by increasing their commitment to the cause, feeling that it is only fair that they should act. In contrast, if those with power and status do nothing to tackle climate change, it is easy to see how our data might suggest that people would be less willing to take action, perceiving such action as less just. In this sense our findings suggest that the moral 
domain of justice (see Haidt, 2007) may be an important driver of pro-environmental action. Future work would do well to examine the impact of social influence processes on how fair people perceive pro-environmental actions to be. Rather than focusing on the problem (climate change) as moral or immoral our work suggests that a focus on the moral fairness of necessary actions may be one effective way of recruiting our moral psychology in order to tackle climate change.

Here we have taken the first few steps toward exploring the potential for social influence based on status and group membership to influence our pro-environmental action though our moral judgments of fairness. However, the current research has various limitations that should be considered when drawing any strong conclusions, particularly for the purposes of informing current policy and action. It is possible that the absence of some group-based influence effects may be due to a failure of the model identity manipulation to provided an explicit enough inter-group comparison (see Abrams et al., 1990). That said, the fact that we do find some direct, indirect, and conditional effects of group membership suggests that our paradigm was sufficient enough to trigger social categorization and group-based influence processes. Future work would do well to manipulate the salience of inter-group comparisons to examine whether our effects are conditional on degree of social identity salience (see Rabinovich et al., 2011). Although our results demonstrate strong evidence for the predictive role of moral judgments of the fairness of pro-environmental action across student, non-student, British, and American samples, there is still some inconsistency across studies in terms of the specific behaviors that high status ingroup members engender through the justice pathway. Future work would also do well to explore possible differences between student and non-student samples as well as cultural differences in responses to high status ingroup models. Furthermore, longitudinal field-experimental designs could be employed in order to better understand the psychological processes through which social models influence objective measures of proenvironmental behavior. In contrast to the conventional techniques employed here for testing mediation (see Hayes, 2013; MacKinnon, Fairchild, \& Fritz, 2007), longitudinal designs would offer the chance to use dynamic mediation approaches that involve testing whether interventions leads to change in one outcome, which then predicts change in another, providing a more direct test of the psychological processes involved (Coman, Iordache, \& Coman, 2013; see also Montoya \& Hayes, n.d.).

Taken together, our findings suggest that although aspects of our social and moral cognition may act as a barrier or, worse still, a "dragon on inaction" (Gifford, 2011) with regard to climate change, they also provide an opportunity for us to employ what we know about the structure of the human mind in pursuit of addressing one of the greatest known risks to human and non-human life.

\section{Notes}

1. We also included measures of how costly and effective participants perceived the model's actions to be and various measures to tap positive and negative feelings 
toward the models. There were no main effects of model status, identity, or any interaction effect on the perceived costliness $\left(F(1,123)=1.59, p=.21, \eta_{p}^{2}=0.01\right.$, $F(1,123)=1.18, p=.28, \eta_{p}^{2}=0.01$, and $F(1,123)=1.13, p=.29, \eta_{p}^{2}=0.01$, respectively) or effectiveness $\left(F(1,124)=2.61, p=.11, \eta_{p}^{2}=0.02, F(1,124)=\right.$ $1.15, p=.29, \eta_{p}^{2}=0.009$, and $F(1,124)=0.50, p=.48, \eta_{p}^{2}=0.004$, respectively) of the model's action. Similarly, there were no main effects of model status, identity, or any interaction effect with our evaluative measures toward the model, $F(1,124)=0.40, p=.53, \eta_{p}^{2}=0.003, F(1,124)=0.51, p=.48, \eta_{p}^{2}=0.004$, and $F(1,124)=1.31, p=.25, \eta_{p}^{2}=0.01$, respectively. We also took measures of the perceived costliness and effectiveness of each pro-environmental action. Adding these additional measures to our statistical model made no significant difference to the interpretation of our results.

2. We did not plan to exclude partieipations that failed to report the correct group membership of the social model. We are thankful to an anonymous reviewer who suggested undertaking a separate analysis.

\section{References}

Abrams, D., Wetherell, M., Cochrane, S., Hogg, M. A., \& Turner, J. C. (1990). Knowing what to think by knowing who you are: Self-categorization and the nature of norm formation, conformity and group polarization. British Journal of Social Psychology, 29(2), 97-119. doi: 10.1111/j.20448309.1990.tb00892.x

Anderson, K. (2013). Why carbon prices can't deliver the $2^{\circ} \mathrm{C}$ target. Available at: http://kevinanderson.info/ blog/why-carbon-prices-cant-deliver-the-2c-target/. Accessed June 17, 2014.

Anderson, C., John, O. P., Keltner, D., \& Kring, A. M. (2001). Who attains social status? Effects of personality and physical attractiveness in social groups. Journal of Personality and Social Psychology, 81 (1), 116-132. doi: 10.1037//0022-3514.81.1.116

Anderson, C. A., Lindsay, J. J., \& Bushman, B. J. (1999). Research in the psychological laboratory: Truth or triviality? Current Directions in Psychological Science, 8(1), 3-9. doi: 10.2307/20182544?ref=no-x-route: c2aa14a933f3ce985e12e57e883c423f

Aristotle, ???. (2005). The art of rhetoric. London, UK: Penguin.

Aronson, E. (2007). The social animal (10th ed.). New York, NY: Worth Pub.

Asch, S. (1955). Opinions and social pressure. Scientific American, 192(5), 31-35. doi: 10.1038/ scientificamerican1155-31

Bamberg, S., \& Möser, G. (2007). Twenty years after Hines, Hungerford, and Tomera: A new meta-analysis of psycho-social determinants of pro-environmental behaviour. Journal of Environmental Psychology, 27 (1), 14-25. doi: 10.1016/j.jenvp.2006.12.002

Bandura, A. (1977). Social learning theory. New York, NY: General Learning Press.

Burn, S. M. (1991). Social psychology and the stimulation of recycling behaviors: The block leader approach. Journal of Applied Social Psychology, 21(8), 611-629. doi: 10.1111/j.1559-1816.1991.tb00539.x

Cialdini, R. B. (2001). Influence: Science and practice (4th ed). Boston, MA: Allyn \& Bacon.

Coman, E., Iordache, E., \& Coman, M. (2013). Testing mediation the way it was meant to be: leading to changes then to other changes. Dynamic mediation implemented with latent change scores (pp. 1-35). at the Modern Modeling Methods Conference, Storrs, CT. http:// www.modeling.uconn.edu/m3c/assets/File/Coman_mediation\%20the\%20way\%20it\%20was\%20meant.pdf. 
Darley, J. (1990). Moral rules: Their content and acquisition. Annual Review of Psychology, 41, 525-556. doi: 10.1146/annurev.ps.41.020190.002521

Dietz, T., Gardner, G. T., Gilligan, J., Stern, P. C., \& Vandenbergh, M. P. (2009). Household actions can provide a behavioral wedge to rapidly reduce US carbon emissions. Proceedings of the National Academy of Sciences of the United States of America, 106(44), 18452-18456. doi: 10.1073/pnas.0908738106

Fehr, R., Yam, K. C., \& Dang, C. (2015). Moralized leadership: The construction and consequences of ethical leader perceptions. Academy of Management Review, 40(2), 182-209. doi: 10.5465/amr.2013.0358

Feinberg, M., \& Willer, R. (2013). The moral roots of environmental attitudes. Psychological Science, 24(1), 56-62. doi: 10.1177/0956797612449177

Fiske, S. T., Cuddy, A. J. C., \& Glick, P. (2007). Universal dimensions of social cognition: Warmth and competence. Trends in Cognitive Sciences, 11(2), 77-83. doi: 10.1016/j.tics.2006.11.005

Fritz, M. S., \& MacKinnon, D. P. (2007). Required sample size to detect the mediated effect. Psychological Science, 18(3), 233-239. doi: 10.1111/j.1467-9280.2007.01882.x

Gifford, R. (2011). The dragons of inaction: Psychological barriers that limit climate change mitigation and adaptation. American Psychologist, 66 (4), 290-302. doi: 10.1037/a0023566

Haidt, J. (2001). The emotional dog and its rational tail: A social intuitionist approach to moral judgment. Psychological Review, 108 (4), 814-834. doi: 10.1037/0033-295X.108.4.814

Haidt, J. (2007). The new synthesis in moral psychology. Science, 316(5827), 998-1002.

Hayes, A. F. (2013). Introduction to mediation, moderation, and conditional process analysis. New York, NY: Guilford Press.

Henrich, J., \& Gil-White, F. J. (2001). The evolution of prestige: Freely conferred deference as a mechanism for enhancing the benefits of cultural transmission. Evolution and Human Behavior, 22 (3), 165-196. doi: 10.1016/S1090-5138(00)00071-4

Hewstone, M., Rubin, M., \& Willis, H. (2002). Intergroup bias. Annual Review of Psychology, 53 (1), 575604. doi:10.1146/annurev.psych.53.100901.135109

Hines, J. M., Hungerford, H. R., \& Tomera, A. N. (1987). Analysis and synthesis of research on responsible environmental behavior: A meta-analysis. The Journal of Environmental Education, 18 (2), 1-8. doi:10.1080/00958964.1987.9943482

Hogg, M. A. (2001). A social identity theory of leadership. Personality and Social Psychology Review, 5, 184-200. doi:10.1207/S15327957PSPR0503_1

Hopper, J. R., \& Nielsen, J. M. (1991). Recycling as altruistic behavior normative and behavioral strategies to expand participation in a community recycling program. Environment and Behavior, 23 (2), 195-220. doi:10.1177/0013916591232004

Insel, T. R., \& Fernald, R. D. (2004). How the brain processes social information: Searching for the social brain. Annual Review of Neuroscience, 27 (1), 697-722. doi:10.1146/annurev.neuro.27.070203. 144148

IPCC. (2014). Summary for Polieymakers. In Climate thange 2014: Mitigan ef elimate Ehange. Gontribution of Working Group III to the Fifth Assescment Report of the Intergovernment Panel on Elim Ehange (pp. 133). 2??: Eambridge University Press. Available at: http:// report.mitigation2014.org/spm/ipcc_wg3_ar5_summary-for-policymakers_approved.pdf.

Jetten, J., \& Spears, R. (1996). Intergroup norms and intergroup discrimination: Distinctive selfcategorization and social identity effects. Journal of Personality and Social Psychology, 71, 1222-1233. doi: 10.1037/0022-3514.71.6.1222

Keltner, D., Van Kleef, G. A., Chen, S., \& Kraus, M. W. (2008). A reciprocal influence model of social power: Emerging principles and lines of inquiry. Advances in Experimental Social Psychology, 40, 151192. doi:10.1016/S0065-2601(07)00003-2

Lorenzoni, I., Nicholson-Cole, S., \& Whitmarsh, L. (2007). Barriers perceived to engaging with climate change among the UK public and their policy implications. Global Environmental Change, 17(3-4), 445459. doi: 10.1016/j.gloenvcha.2007.01.004 
MacKinnon, D. P., Fairchild, A. J., \& Fritz, M. S. (2007). Mediation analysis. Annual Review of Psychology, 58, 593-614. doi: 10.1146/annurev.psych.58.110405.085542

Markowitz, E. M., \& Shariff, A. F. (2012). Climate change and moral judgement. Nature Climate Change, 2 (4), 243-247. doi: 10.1038/nclimate1378

Montoya, A., \& Hayes, A. F. (n.d.). Two-condition within-participant statistical mediation analysis: A pathanalytic framework, 158.

Osbaldiston, R., \& Schott, J. P. (2012). Environmental sustainability and behavioral science: Meta-analysis of proenvironmental behavior experiments. Environment and Behavior, 44 (2), 257-299. doi: 10.1177/ 0013916511402673

Rabinovich, A., Morton, T. A., Postmes, T., \& Verplanken, B. (2011). Collective self and individual choice: The effects of inter-group comparative context on environmental values and behaviour. British Journal of Social Psychology, 51 (4), 551-569. doi: 10.1111/j.2044-8309.2011.02022.x

Rawls, J. (1971). A theory of justice. Cambridge, MA: Harvard University Press.

Sears, D. O. (1986). College sophomores in the laboratory: Influences of a narrow data base on social psychology's view of human nature. Journal of Personality and Social Psychology, 51, 515-530. doi: 10.1037/0022-3514.51.3.515

Sherif, M. (1936). The psychology of social norms. New York, NY: Harper \& Row.

Stúrmer, S., \& Simon, B. (2004). Collective action: Towards a dual-pathway model. European Review of Social Psychology, 15 (1), 59-99. doi: 10.1080/10463280340000117

Sweetman, J., Spears, R., Livingstone, A. G., \& Manstead, A. S. R. (2013). Admiration regulates social hierarchy: Antecedents, dispositions, and effects on intergroup behavior. Journal of Experimental Social Psychology, 49 (3), 534-542. doi: 10.1016/j.jesp.2012.10.007

Tajfel, H., \& Turner, J. C. (1979). An integrative theory of intergroup conflict. In W. G. Austin \& S. Worchel (Eds.), The social psychology of intergroup relations (pp. 33-48). Monterey, CA: Brooks/Cole.

Turner, J. C. (1991). Social influence. Belmont, CA: Wadsworth Publishing.

Tyler, T. R., Boeckmann, R. J., Smith, H. J., \& Huo, Y. J. (1997). Social justice in a diverse society. Oxford, UK: Westview Press.

Tyler, T. R., \& Dawes, R. M. (1993). Fairness in groups: Comparing the self-interest and social identity perspectives. In B. A. Mellers, \& J. Baron (Eds.), Psychological perspectives on justice (pp. 87-108). New York, NY: Cambridge University Press.

Van Zant, A. B., \& Moore, D. A. (2015). Leaders' use of moral justifications increases policy support. Psychological Science, 26 (6), 934-943. doi: 10.1177/0956797615572909

Van Zomeren, M., Postmes, T., \& Spears, R. (2008). Toward an integrative social identity model of collective action: A quantitative research synthesis of three socio-psychological perspectives. Psychological Bulletin, 134 (4), 504-535. doi: 10.1037/0033-2909.134.4.504

Van Zomeren, M., Spears, R., Fischer, A. H., \& Leach, C. W. (2004). Put your money where your mouth Is! Explaining collective action tendencies through group-based anger and group efficacy. Journal of Personality and Social Psychology, 87 (5), 649-664. doi: 10.1037/0022-3514.87.5.649

Whitmarsh, L., \& O'Neill, S. (2010). Green identity, green living? The role of pro-environmental selfidentity in determining consistency across diverse pro-environmental behaviours. Journal of Environmental Psychology, 30 (3), 305-314. doi: 10.1016/j.jenvp.2010.01.003

Winett, R. A., Leckliter, I. N., Chinn, D. E., Stahl, B., \& Love, S. Q. (1985). Effects of television modeling on residential energy conservation. Journal of Applied Behavior Analysis, 18 (1), 33-44. doi: 10.1901/ jaba.1985.18-33 